\title{
Nonintrusive Method for Induction Motor Equivalent Circuit Parameter Estimation using Chicken Swarm Optimization (CSO) Algorithm
}

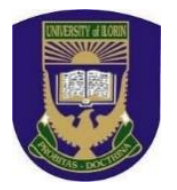

\author{
M. Aminu ${ }^{1 *}$, M. Abana ${ }^{1}$, S. W. Pallam ${ }^{1}$, P. K. Ainah ${ }^{2}$ \\ ${ }^{1}$ Department of Electrical Engineering, Modibbo Adama University of Technology Yola, Nigeria. \\ ${ }^{2}$ Department of Electrical Engineering, Niger Delta University, Wilberforce Island, Bayelsa, Nigeria.
}

ABSTRACT: This paper presents a nonintrusive method for estimating the parameters of an Induction Motor (IM) without the need for the conventional no-load and locked rotor tests. The method is based on a relatively new swarmbased algorithm called the Chicken Swarm Optimization (CSO). Two different equivalent circuits implementations have been considered for the parameter estimation scheme (one with parallel and the other with series magnetization circuit). The proposed parameter estimation method was validated experimentally on a standard $7.5 \mathrm{~kW}$ induction motor and the results were compared to those obtained using the IEEE Std. 112 reduced voltage impedance test method 3. The proposed CSO optimization method gave accurate estimates of the IM equivalent circuit parameters with maximum absolute errors of $5.4618 \%$ and $0.9285 \%$ for the parallel and series equivalent circuits representations respectively when compared to the IEEE Std. 112 results. However, standard deviation results in terms of the magnetization branch parameters, suggest that the series equivalent circuit model gives more repeatable results when compared to the parallel equivalent circuit.

KEYWORDS: Induction motor, Chicken Swarm Optimization, parameter estimation, equivalent circuit, objective function

\section{INTRODUCTION}

Induction motors are the primary source of mechanical energy for various industrial applications. They constitute nearly $80 \%$ of the total number of motors used in industries (Fleiter et al, 2011; Waide and Brunner, 2011). This is mainly due to their low cost, reliability, robustness and low maintenance cost when compared to other types of machines. In high performance electric drive systems such as the Field Oriented Control (FOC) or the Direct Torque Control (DTC), accurate parameter estimation is needed to guarantee good controller response and overall performance (Toliyat et al, 2003). Significant attention has been given to the development of new methods for Induction Motor (IM) parameters estimation.

Currently, the standard no-load and locked rotor tests are the most reliable procedures that are being used to determine the IM equivalent circuit parameters. However, because these two tests represent the extremes of the motor operation, they do not correspond to normal conditions under which the IM operates. In addition, these tests may not be easily performed under in-service condition because of their intrusive nature, since the no-load test involves running the motor uncoupled to a load, while the locked rotor test requires full control of the rotor mechanically in the locked condition before measurements are taken. Hence, alternative methods have been considered in literature for IM parameters estimation.
A review of the major parameter estimation techniques has been presented in (Toliyat et al, 2003). Generally, the methods can be classified into two major groups, namely: signal injection methods and system identification methods. Signal injection methods are usually performed at standstill with the motor excited using a dc or ac signal and the motor parameters are determined based on the resulting response. Several studies using signal injection method are reported (Carraro and Zigliotto, 2014; Bechouche et al, 2012; Castaldi and Tilli, 2005). However, the major drawback of this method is the problem of torque ripples due to the injected signal ( $\mathrm{Lu}$ et al, 2008). System identification methods can be based on steady state measurements (Reed et al, 2016; Alturas et al, 2016; Haque, 2008; Abdelhadi et al, 2005; Cirrincione et al, 2005) or transient measurements (Ranta and Hinkkanen, 2013; Wang., et al, 2004). Steady state methods use simplified motor models to solve the parameter estimation problem but require multiple tests measurements at different loading conditions.

Optimization techniques that are inspired by the phenomenon of natural evolution and Swarm Intelligence (SI) have been applied for IM parameter estimation (Al-badri et al, 2015; Kanakoglu et al, 2014; Seesak and Panthep, 2009). These methods rely on measurements of the motor terminal voltages and currents under steady state operation. Thus, the no-load and locked rotor test are avoided, making them suitable for field or in-service applications. Generally, 
optimization methods are based on error minimization criterion. In this paper, the error function for optimization is defined by the percentage difference between the measured (experimental) and the estimated stator current, input and output power and the power factor. The optimization problem is then solved using the CSO optimization algorithm.

\section{MODELLING AND PROBLEM FORMULATION}

\section{A. Steady-state Model of an Induction Machine}

The stator and rotor voltage equations of a squirrel cage IM under a balanced sinusoidal supply and in the steady state operating condition as presented in (Mohan, 2012) is given by:

$$
\begin{aligned}
& \bar{v}_{s d q}=r_{s} \bar{l}_{s d q}+j \omega_{s y n} \bar{\lambda}_{s d q} \\
& 0=\frac{r_{r}}{s} \bar{l}_{r d q}+j \omega_{s y n} \bar{\lambda}_{r d q}
\end{aligned}
$$

where $\mathrm{s}$ is the slip. Substituting the flux linkage space vectors in (1) and (2) gives:

$$
\begin{aligned}
& \bar{v}_{s d q}=r_{s} \bar{l}_{s d q}+j x_{l s} \bar{l}_{s d q}+j x_{m}\left(\bar{l}_{s d q}+\bar{l}_{r d q}\right) \\
& 0=\frac{r_{r}}{s} \bar{l}_{r d q}+j x_{l r} \bar{l}_{r d q}+j x_{m}\left(\bar{l}_{s d q}+\bar{l}_{r d q}\right)
\end{aligned}
$$

The space vector equations (3) and (4) corresponds to the following phasor equations.

$$
\begin{aligned}
& v_{s}=r_{s} I_{s}+j x_{l s} I_{s}+j x_{m}\left(I_{s}+I_{r}\right) \\
& 0=\frac{r_{r}}{s} I_{r}+j x_{l r} I_{r}+j x_{m}\left(I_{s}+I_{r}\right)
\end{aligned}
$$

Combining (5) and (6) results in the per-phase equivalent circuit of an IM as shown in Fig. 1.

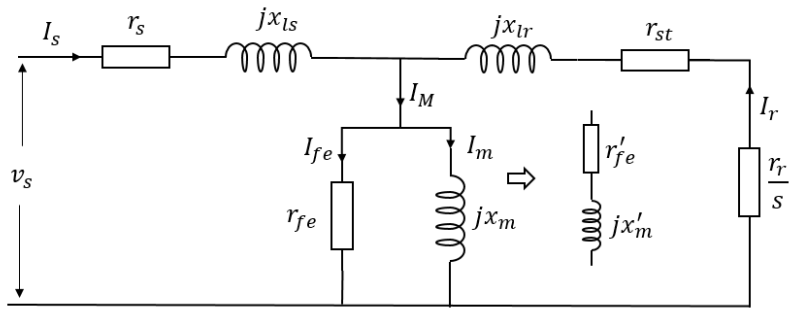

Fig. 1: Equivalent circuit of an Induction Motor

The resistances $r_{f e}$ and $r_{s t}$ are added to the equivalent circuit to account for the core loss and the stray load loss in the motor. The value of $r_{s t}$ can be determined according to IEEE standard 112 (IEEE Std. 112, 2017) using the equation:

$$
r_{s t}=0.018 r_{r} \frac{\left(1-s_{f l}\right)}{s_{f l}}
$$

where $s_{f l}$ is the slip at full-load.

The parameters associated with the equivalent circuit are the resistance and leakage reactance of the stator and rotor, the core loss resistance and the magnetization reactance. Detail procedures for obtaining these parameters are presented in the next sections.

The parameter estimation method uses the steady-state equivalent circuit of an IM to derive an objective function for optimization. In most conventional T-models, the core loss resistance is omitted for simplicity. However, in applications such as efficiency estimation or the design of highperformance electric drive systems, the core loss is crucial and therefore must be considered (Yang et al, 2017). In this paper, two equivalent circuit implementations are used: one with a parallel and the other with a series core loss representation as depicted in Fig. 1.

\section{B. Objective Function Formulation}

The goal of the optimization is to search for the motor parameters by minimizing the error between the measured and estimated motor quantities such as the stator currents, input power, output power and power factor using measured (experimental) and estimated (computer generated data). In order to minimize the number of unknown variables for the optimization algorithm, the resistance of the stator winding $r_{S}$ can be obtained through direct measurements across two terminals of the stator windings (IEEE Std. 112, 2017). For a star connected machine, the stator resistance is given by equation (8) (IEEE Std. 112, 2017).

$$
r_{s}=0.5 r_{\text {total }}
$$

where $r_{\text {total }}$ is the resistance measured across the two stator terminals.

The ratio of stator to rotor reactance can also be used to determine the stator reactance based on the NEMA design class of the machine (NEMA MG 1, 2006) as shown in Table 1.

\begin{tabular}{cc} 
Table 1: Ratio of $\boldsymbol{x}_{\boldsymbol{s}} / \boldsymbol{x}_{\boldsymbol{r}}$ based on NEMA design class. \\
\hline $\boldsymbol{x}_{\boldsymbol{s}} / \boldsymbol{x}_{\boldsymbol{r}}$ & NEMA Design class \\
\hline$x_{s} / x_{r}=0.67$ & $\mathrm{~B}$ \\
$x_{s} / x_{r}=0.43$ & $\mathrm{C}$ \\
$x_{s} / x_{r}=1.00$ & A, D and wound rotor motors \\
\hline
\end{tabular}

With the stator resistance and reactance determined, only four variables are to be searched using the optimization techniques. These parameters are the rotor resistance $\left(r_{r}\right)$, the core loss resistance $\left(r_{f e}\right)$, the rotor leakage reactance $\left(x_{l r}\right)$ and the magnetization reactance $\left(x_{m}\right)$.

Since values of resistances are affected by temperature changes, the stator and rotor resistances are to be corrected according to IEEE Standard 112 (IEEE Std. 112, 2017) using equation (9):

$$
R_{t}=R_{m}\left(\frac{T_{t}+C}{T_{m}+C}\right)
$$

where $R_{m}$ is the measured value of winding resistance at the measured temperature $T_{m}$ and $R_{t}$ is the winding resistance corrected to the full-load temperature $T_{t} . C$ is the zeroresistance temperature constant $(\mathrm{C}=234.5$ for copper and $\mathrm{C}=$ 224.1 for aluminum).

Thus, the corrected resistances for the stator and rotor are:

$$
\begin{aligned}
& r_{s-c}=r_{\text {stator }}\left(\frac{T_{t}+C}{T_{m}+C}\right) \\
& r_{r-c}=r_{\text {rotor }}\left(\frac{T_{t}+C}{T_{m}+C}\right)
\end{aligned}
$$

The following equations can be derived based on the equivalent circuit shown in Fig.1:

$$
\begin{aligned}
& Y_{s}=\frac{1}{r_{s-c}+j x_{s}} \\
& Y_{r}=\frac{1}{\frac{r_{r}}{s}+r_{s t}+j x_{r}}
\end{aligned}
$$

For parallel magnetizing circuit: 


$$
\begin{gathered}
Y_{m}=\frac{1}{r_{f e}}-\frac{j}{x_{m}} \\
I_{s-e s t}=\left|\frac{v_{s} Y_{S}\left(Y_{r}+Y_{m}\right)}{Y_{s}+Y_{r}+Y_{m}}\right| \\
I_{m}=\left|\frac{v_{s} Y_{s}}{r_{f e}\left(Y_{s}+Y_{r}+Y_{m}\right)}\right| \\
p f_{\text {est }}=\frac{\text { Real }\left(I_{s}\right)}{I_{s-e s t}} \\
I_{r}=\left|\frac{v_{s} Y_{S} Y_{r}}{Y_{s}+Y_{r}+Y_{m}}\right| \\
P_{\text {input-est }}=3\left(I_{s}^{2} r_{s-c}+I_{r}^{2}\left(\frac{r_{r-c}}{s}+r_{s t}\right)+I_{m}^{2} r_{f e}\right) \\
P_{\text {output }-e s t}=3 I_{r}^{2} r_{r-c}\left(\frac{1-s}{s}\right)
\end{gathered}
$$

The parallel magnetization branch shown in Fig. 1 can be transformed into a series connection (Sandro et al, 2017) and the series resistance $\left(r_{m}^{\prime}\right)$ and reactance $\left(x_{m}^{\prime}\right)$ expressed as:

$$
\begin{aligned}
r_{f e}^{\prime} & =\frac{x_{m}^{2} r_{f e}}{r_{f e}^{2}+x_{m}^{2}} \\
x_{m}^{\prime} & =\frac{r_{f e}^{2} x_{m}}{r_{f e}^{2}+x_{m}^{2}}
\end{aligned}
$$

Thus, the series admittance is:

$$
Y_{m}^{\prime}=\frac{1}{r_{f e}^{\prime}+j x_{m}^{\prime}}
$$

$Y_{m}^{\prime}$ as presented in equation (23), is used as the magnetization admittance in (15), (16) and (18) for the series magnetization circuit.

The goal of optimization is to continuously update the motor parameters by minimize the error between the measured and estimated quantities defined by the following functions:

$$
\begin{aligned}
f_{1} & =\left(\frac{I_{s-e s t}-I_{S}}{I_{S}}\right) \times 100 \\
f_{2} & =\left(\frac{P_{\text {input }- \text { est }}-P_{\text {input }}}{P_{\text {input }}}\right) \times 100 \\
f_{3} & =\left(\frac{p f_{\text {est }}-p f}{p f}\right) \times 100 \\
f_{4} & =\left(\frac{P_{\text {output-est }}-P_{\text {output }}}{P_{\text {output }}}\right) \times 100
\end{aligned}
$$

The objective function to be minimized is therefore as given in (28):

$$
f_{o b j}=\sum_{i=1}^{n}\left(\sum_{j=1}^{m} f_{j}^{2}\right)_{i}
$$

subject to the inequality parameter vector constraint:

$$
P(\theta)_{-\min } \leq P(\theta) \leq P(\theta)_{-\max }
$$

Where $n$ and $m$ are the number of load points and the number of measured data respectively, $\theta=\left[r_{r}, x_{l r}, r_{f e}, x_{m}\right]$ is a vector containing the unknown motor parameters.

\section{The CSO Optimization Algorithm}

The Chicken swarm optimization (CSO) is a new bioinspired swarm optimization algorithm introduced in 2014 by (Meng et al, 2014). The algorithm is inspired by the hierarchal order and dominance behaviour of chickens in a swarm. The chicken swarm is divided into several groups with each group having a dominant rooster followed by some hens and chicks. The chickens with the best and worst fitness values are selected as the roosters and chicks respectively, while the remaining chickens are taken as the hens. Formulation of the algorithm involves defining randomly, the positions of each individual chicken in the swarm. If $R N, H N, C N$ and $M N$ represent the number of roosters, hens, chicks and mother hens respectively, all $N$ virtual chickens are defined by their positions $x_{i, j}^{t}(i \in[1,2,3, \ldots, N], j \in[1,2,3, \ldots, D])$ at time $t$. where $N$ is the total population of chickens in the swarm and $D$ is the dimension or boundary within which the chickens search for food.

The roosters with better fitness value can search for food in a wider range than those with worst fitness values. This is defined by the position equation (Meng et al, 2014) given in equation (30):

$$
\begin{aligned}
& x_{i, j}^{t+1}=x_{i, j}^{t} *\left(1+\operatorname{Randn}\left(0, \sigma^{2}\right)\right) \\
& \sigma^{2}=\left\{\begin{array}{c}
1, \quad \text { if } \quad f_{i} \leq f_{k} \\
\exp \left(\frac{f_{k}-f_{i}}{\left|f_{i}\right|+\varepsilon}\right), \text { otherwise }
\end{array}\right.
\end{aligned}
$$

Where $k \in[1, N], k \neq i, \quad \operatorname{Randn}\left(0, \sigma^{2}\right)$ is a Gaussian distribution with mean 0 and standard deviation $\sigma^{2}, \varepsilon$ is the smallest constant used to avoid zero division. $k$ is the rooster's index and $f$ is the fitness value.

For the hens, the dominant would have more advantage in competing for food than the submissive ones. This can be formulated as follows (Wu et al, 2015; Meng et al, 2014):

$$
\begin{gathered}
x_{i, j}^{t+1}=x_{i, j}^{t}+S 1 * \operatorname{Rand}[0,1] *\left(x_{r 1, j}^{t}-x_{i, j}^{t}\right)+S 2 * \\
\operatorname{Rand}[0,1] *\left(x_{r 2, j}^{t}-x_{i, j}^{t}\right) \\
S 1=\exp \left(\frac{f_{i}-f_{r 1}}{a b s\left(f_{i}\right)+\varepsilon}\right) \\
S 2=\exp \left(f_{r 2}-f_{i}\right)
\end{gathered}
$$

where $r 1 \in[1,2,3, \ldots, N]$ is the rooster's index in the $i^{t h}$ group, while $r 2 \in[1,2,3, \ldots, N]$ is the index of chicken (rooster or hen) randomly chosen from the swarm but $r 1 \neq r 2$.

The chicks forage for food around their mother. This is formulated by (35) (Qu et al, 2017; Meng et al, 2014).

$$
x_{i, j}^{t+1}=x_{i, j}^{t}+F L *\left(x_{m, j}^{t}-x_{i, j}^{t}\right)
$$

where $x_{m, j}^{t}$ is the position of the $i^{t h}$ chick's mother ( $m \in$ $[1, N])$. The parameter $F L(F L \in(0,2))$ is randomly chosen to determine the distance of the chick from its mother.

The six parameters $R N, H N, C N, M N G$ and $F L$ are to be correctly specified in the CSO algorithm. As suggested in $(\mathrm{Wu}$ et $a, 2015$ ), the following parameter assumptions works well for most optimization problems: $R N=0.2 N, H N=$ $0.6 N, C N=N-R N-H N, M N=0.1 N$. Selection of the appropriate value for $\mathrm{G}$ is problem specific. If $\mathrm{G}$ is very large, convergence rate of the algorithm becomes slow while very small value may result in the algorithm converging to a local optimal solution. It is recommended that $G \in[2,20]$ and $F L \in$ $[0.4,1]$ may give good results for most optimization problems (Meng et al, 2014).

Given the chickens' diverse laws of motion and cooperation between groups, the CSO algorithm strikes a balance between exploration and exploitation of the search space and this feature is what gives it its pre-eminence over other optimization algorithms as clearly demonstrated in $(\mathrm{Qu}$ et al, 2017; Wu et al, 2015; Meng et al, 2014).

For the induction motor parameter estimation problem, each individual chicken position $x_{i, j}^{t}=\left[r_{r}, x_{l r}, r_{f e}, x_{m}\right]$ represents a possible solution to the optimization problem.

\section{IEEE Reduced Voltage Impedance Test}

The IEEE reduced voltage impedance test method 3 is briefly presented in this section. This test method is used to 
accurately extract the parameters of the IM which serve as the reference values for validation of the proposed CSO method. In this method, the motor is run uncoupled or coupled to a reduced load and the voltage is reduced to give the desired slip speed. Measurements of voltage, current, power and temperature are recorded at six different voltage values. The total reactance per phase for each test point is calculated and the values are used to draw a curve of the total reactance per phase versus voltage per phase as shown in Fig. 2 (IEEE Std. 112-2017).

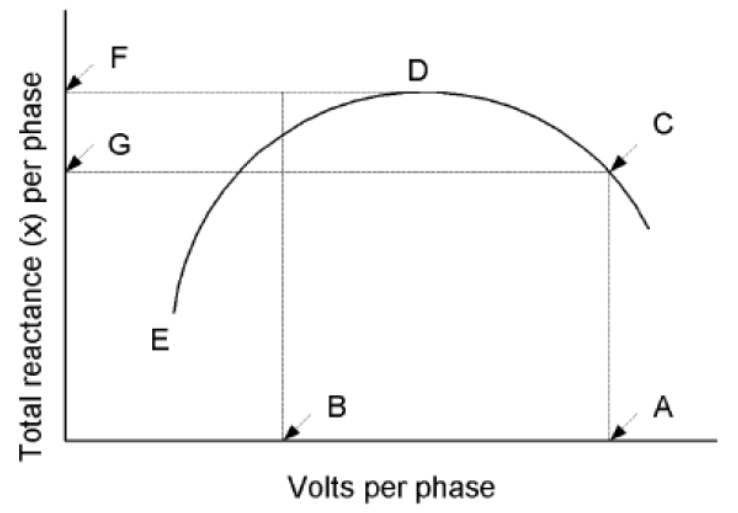

Fig. 2. Total input reactance versus no-load voltage.

The highest point of this curve (D) is taken as the total noload reactance per phase $\left(x_{l s}+x_{m}\right)$. From the lowest voltage test point $(\mathrm{E})$, the total apparent reactance per phase can be calculated (IEEE Std. 112-2017). With the two values obtained at point $\mathrm{D}$ and $\mathrm{E}$, and the initial ratio of $\left(x_{l s} / x_{l r}\right)$ based on the NEMA design class of the motor, the set of equations in section 5.10.5.2 of the IEEE Std. 112-2017 are used iteratively until stable values of the motor parameters are achieved within $0.1 \%$.

\section{RESULTS AND DISCUSSION}

To verify the proposed CSO parameter estimation method, a $7.5 \mathrm{~kW}$ standard efficiency IM with nameplate data given in Table 2 is tested using the experimental setup shown in Fig. 3. The induction motor is coupled to a dynamometer through an in-line torque transducer.

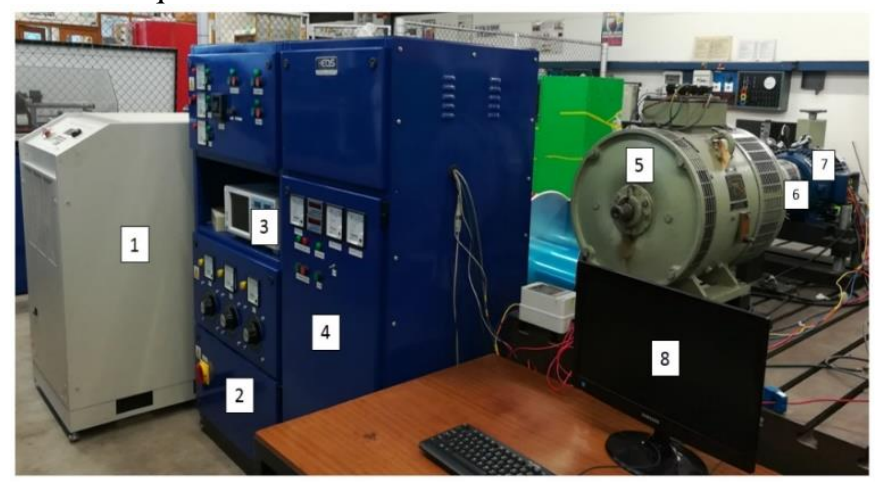

Fig. 3. The $22 \mathrm{~kW}$ Experimental Test Rig: 1. Programmable power supply MX 30, 2. Power supply panel, 3. Yokogowa WT1800 Power Analyzer, 4. 4-Quadrant DC Drive Load Assembly, 5. 15kW DC Machine, 6. In-line torque transducer-Magtrol TM 300, 7. Induction motor, 8. Data acquisition pc.
The IEEE Std. 112 impedance test method 3 was performed and the results obtained are shown in Table 3 . These results are used as the reference values for comparison to the proposed CSO method.

Table 2: Nameplate data of the test motor.

\begin{tabular}{cccccccc}
\hline $\begin{array}{l}\text { Power } \\
(\mathrm{Kw})\end{array}$ & $\begin{array}{c}\boldsymbol{V}_{\text {LL }} \\
(\mathrm{V})\end{array}$ & $\begin{array}{c}\boldsymbol{I}_{\text {Rated }} \\
(\mathrm{A})\end{array}$ & $\begin{array}{l}\text { Freq. } \\
(\mathrm{Hz})\end{array}$ & $\begin{array}{c}\boldsymbol{n}_{\text {Rated }} \\
(\mathbf{r p m})\end{array}$ & poles & Class & Insl. \\
\hline 7.5 & 380 & 15.1 & 50 & 1450 & 4 & $\mathrm{~B}$ & $\mathrm{~F}$ \\
\hline
\end{tabular}

For the CSO method, a rated temperature test as specified by the IEEE standard 112 is first performed. This test is necessary to allow the machine's temperature to stabilize before taking measurements.

Table 3: Estimated parameters based on the IEEE reduced voltage impedance test.

\begin{tabular}{|c|c|c|c|c|c|c|}
\hline $\begin{array}{l}7.5 \mathrm{~kW} \\
\text { Motor }\end{array}$ & $\begin{array}{l}\boldsymbol{R}_{s}{ }^{*} \\
(\boldsymbol{\Omega})\end{array}$ & $\begin{array}{l}\boldsymbol{R}_{r} \\
(\boldsymbol{\Omega})\end{array}$ & $\begin{array}{l}X_{l s} \\
(\boldsymbol{\Omega})\end{array}$ & $\begin{array}{l}X_{l r} \\
(\boldsymbol{\Omega})\end{array}$ & $\begin{array}{l}\boldsymbol{X}_{\boldsymbol{m}} \\
(\boldsymbol{\Omega})\end{array}$ & $\begin{array}{l}\boldsymbol{R}_{f e} \\
(\boldsymbol{\Omega})\end{array}$ \\
\hline $\begin{array}{l}\text { IEEE } \\
\text { std.112 } \\
\text { Parallel } \\
\text { circuit }\end{array}$ & 1.900 & 1.310 & 3.497 & 5.220 & 98.015 & 1400.700 \\
\hline $\begin{array}{l}\text { IEEE } \\
\text { std.112 } \\
\text { Series } \\
\text { circuit }\end{array}$ & 1.900 & 1.310 & 3.497 & 5.220 & 98.500 & 6.893 \\
\hline
\end{tabular}

*Stator resistance is measured directly.

The temperature test is followed by the load test where the machine is subjected to loads at 5 points approximately spaced between $125 \%$ down to $25 \%$ of the rated load. Readings of the stator current, voltage, shaft speed, electrical and mechanical power and the stator winding temperature are taken at each load point. The results from this test are shown in Table 4.

The power factor is calculated for each load point based on Table 4 using Eq. (36).

$$
p f=\frac{P_{\text {elec }}}{\sqrt{3} v_{s} I_{S}}
$$

Table 4: Load test results for the $7.5 \mathrm{~kW}$ test motor.

\begin{tabular}{ccccccc}
\hline $\begin{array}{c}\text { Test } \\
\text { point } \\
(\%)\end{array}$ & $\begin{array}{c}\boldsymbol{v}_{\boldsymbol{s}} \\
(\boldsymbol{V})\end{array}$ & $\begin{array}{c}\boldsymbol{I}_{\boldsymbol{s}} \\
(\boldsymbol{A})\end{array}$ & $\begin{array}{c}\boldsymbol{P}_{\text {elec }} \\
(\boldsymbol{W})\end{array}$ & $\begin{array}{c}\boldsymbol{P}_{\text {mech }} \\
(\boldsymbol{W})\end{array}$ & $\begin{array}{c}\boldsymbol{\omega}_{\boldsymbol{r}} \\
(\boldsymbol{r p m})\end{array}$ & $\begin{array}{c}\text { Temp. } \\
(\boldsymbol{r p m})\end{array}$ \\
\hline 125 & 375.7 & 19.1 & 11,123 & 9,213 & 1,425 & 116.17 \\
100 & 376.9 & 15.2 & 8,731 & 7,471 & 1,445 & 124.28 \\
75 & 378.2 & 11.7 & 6,474 & 5,671 & 1,462 & 118.78 \\
50 & 379.4 & 8.7 & 4,236 & 3,817 & 1,476 & 115.68 \\
25 & 380.4 & 6.5 & 2,294 & 1,925 & 1,489 & 108.88 \\
\hline
\end{tabular}

The data in Table 4 and the calculated power factor for each load point are used as the measured quantities in (24) to (28) to compute the cost function for the CSO optimization algorithm. The code for the CSO optimization was implemented using the Matlab version 2018a software package based on the parameter settings shown in Table 5. The value for $G$ is selected large enough as a tradeoff for the convergence speed in order to avoid a local optimum solution by the CSO algorithm.

Table 5: The parameter settings for the CSO algorithm.

\begin{tabular}{cllccccl}
$\boldsymbol{N}$ & $\boldsymbol{R} \boldsymbol{N}$ & $\boldsymbol{H}$ & $\boldsymbol{C N}$ & $\boldsymbol{M N}$ & $\boldsymbol{G}$ & $\boldsymbol{F L}$ & $\mathrm{D}$ \\
& $(\mathbf{0 . 2}$ & $(\mathbf{0 . 6} *$ & $(\boldsymbol{N}-\boldsymbol{R} \boldsymbol{N}$ & $(\mathbf{0 . 1} *$ & $\in[\mathbf{2}, \mathbf{2 0}]$ & $\in[\mathbf{0 . 4}, \mathbf{1}]$ & \\
& $\boldsymbol{N})$ & $\boldsymbol{N})$ & $-\boldsymbol{H})$ & $\boldsymbol{N})$ & & & \\
\hline 100 & 20 & 60 & 20 & 10 & 10 & 0.6 & 4 \\
\hline
\end{tabular}


Fig. 4(a) to Fig. 4(g) show the convergence of the cost function and the motor parameters using the CSO algorithm for the parallel equivalent circuit. The algorithm is run 30 times with the same input data to test for consistency. Only three optimization cycles are shown in the figures for clarity.
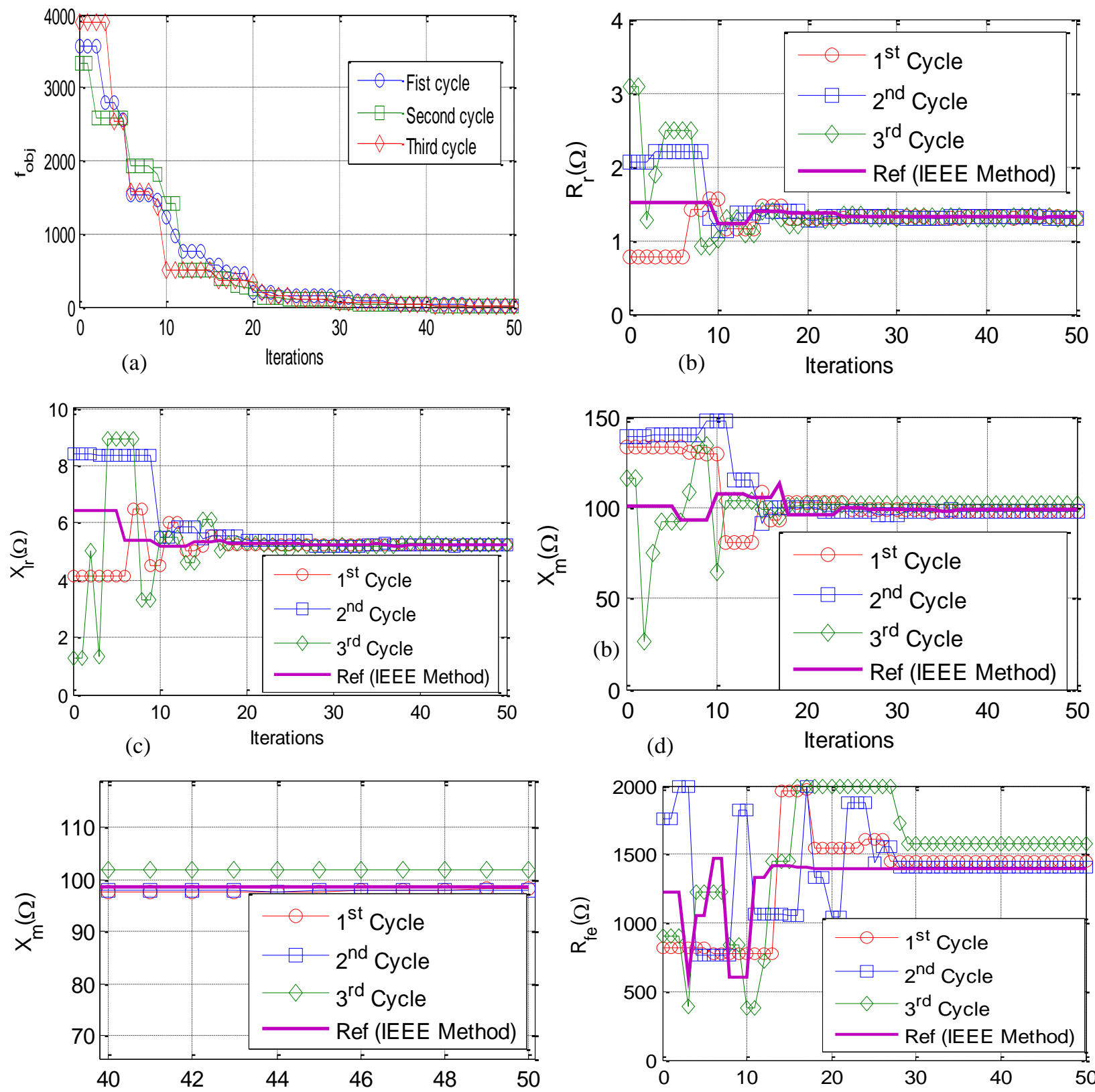

(e)

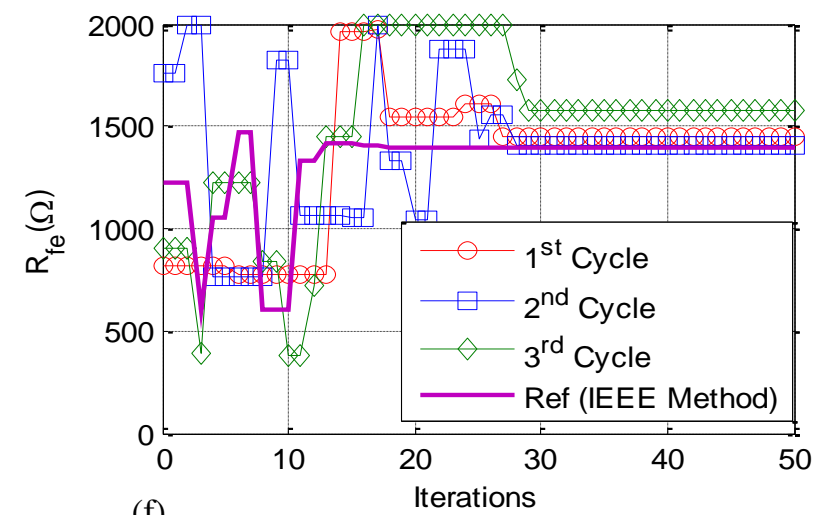

(f)

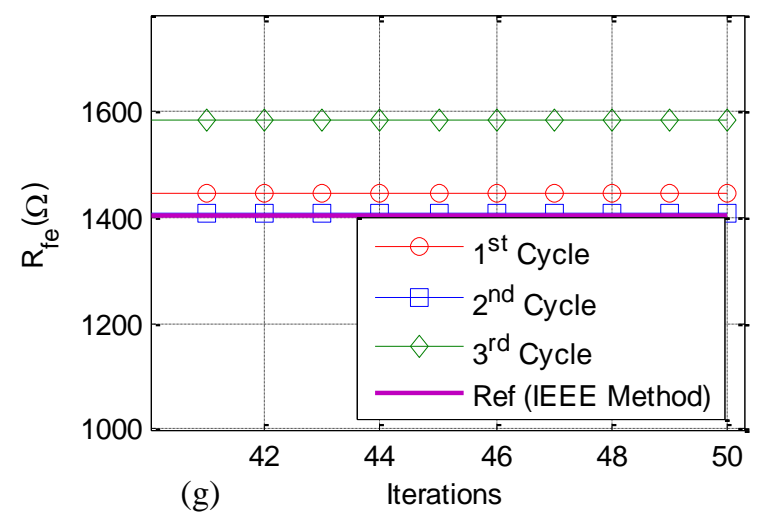

Fig. 4: Convergence profiles (parallel circuit): (a) Objective function (b) Rotor resistance (c) Rotor leakage reactance (d) Magnetization reactance (e) Magnetization reactance (Zoomed) (f) Core loss resistance (g) Core loss resistance (Zoomed). 
As can be seen in Fig. 4(a), the objective function converges after about 42 iterations for all the three cycles. As shown in Fig. 4(b) and Fig. 4(c), consistent steady values of $1.309 \Omega$ and $5.225 \Omega$ were obtained in all 30 optimization cycles for the rotor resistance and leakage reactance respectively. On the other hand, inconsistent results are obtained for the core loss resistance and magnetization reactance as can be seen in Figs. 4(d)-(g). The disparity can be seen to be more pronounced in the estimation of the core loss resistance as can be observed in the Fig. 4(g). This problem has been observed in (Lu et al, 2007) and is due to the small impact of the core loss resistance on the stator IM currents.

One way of solving this problem is to use a series instead of the parallel circuit for the magnetization branch. Fig. 5(a) to Fig. 5(e) show the results for the series equivalent circuit.

As can be observed, the CSO algorithm was able to track the equivalent circuit parameters including the core loss resistance and the magnetization reactance in all the optimization cycles.

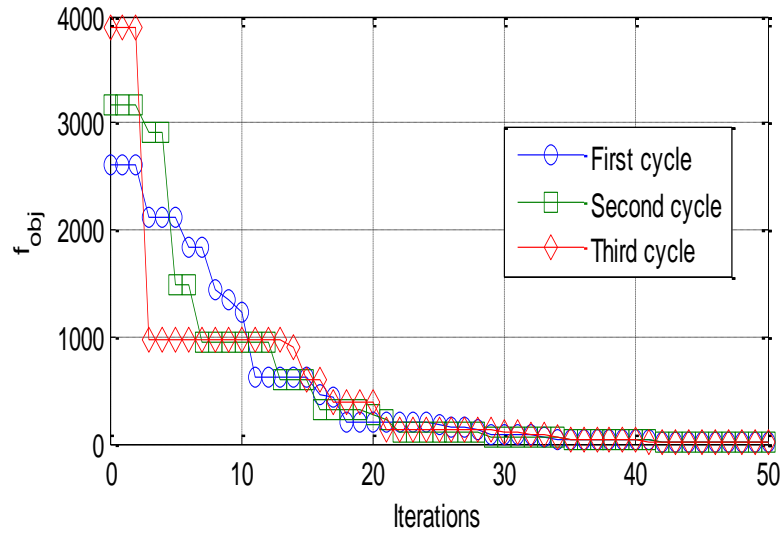

(a)

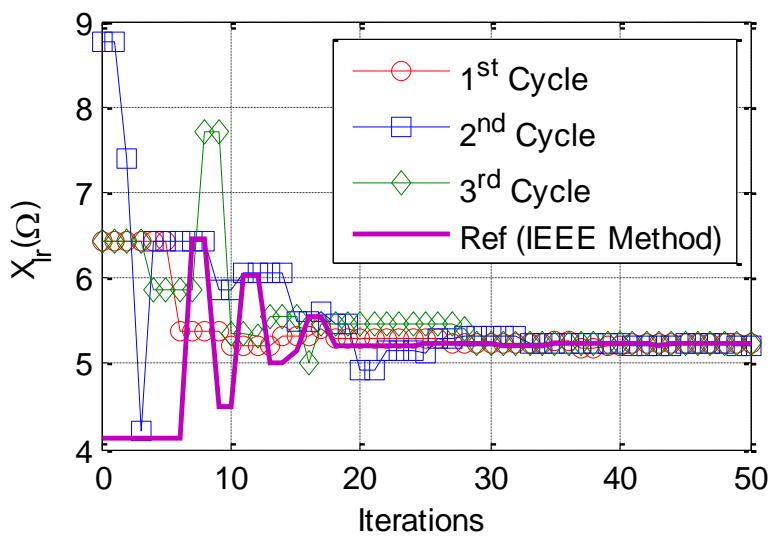

(c)

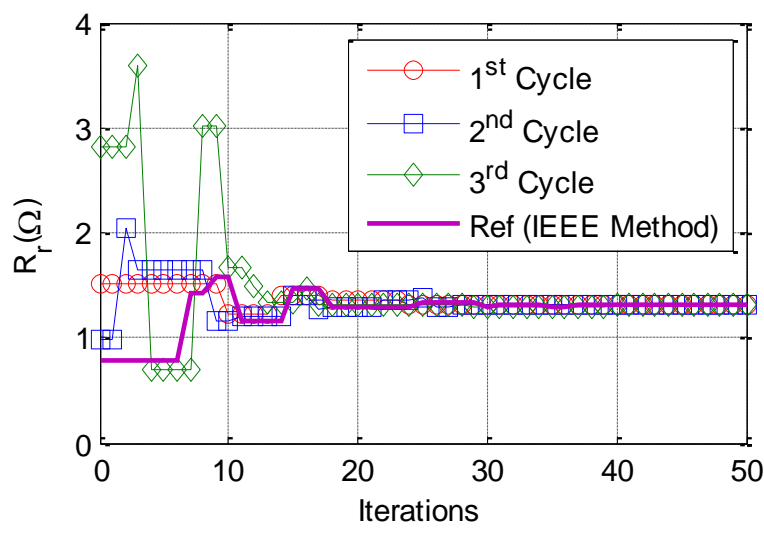

(b)

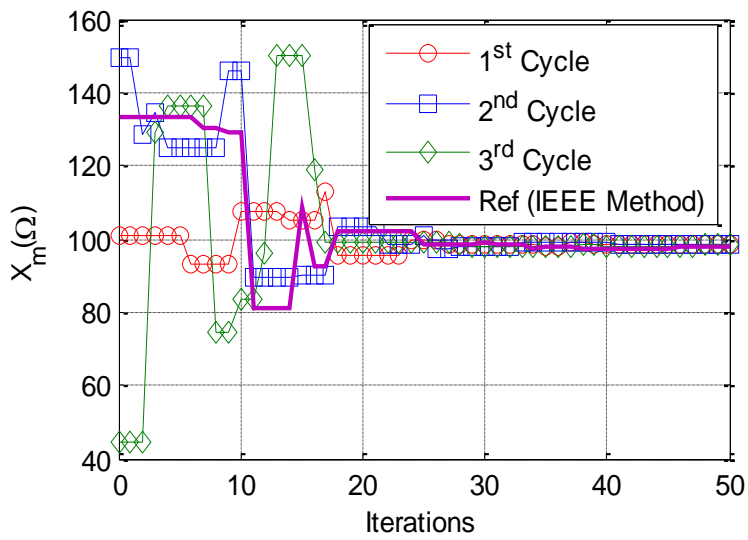

(d)

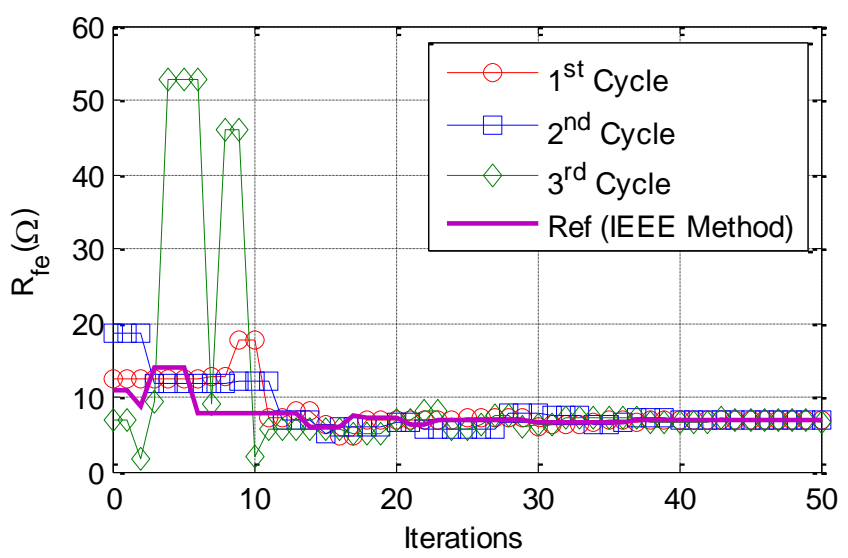

(e)

Fig. 5. Convergence profile (series circuit): (a) objective function (b) Rotor resistance (c) Rotor leakage reactance (d) Magnetization reactance (e) Core loss resistance. 
Table 6 summarizes the final parameter estimation results for the parallel and series equivalent circuits. The CSO algorithm was set to run for 30 cycles and the average value was taken for each parameter. This is necessary to confirm the repeatability of the estimation algorithm. Based on the repeatability test, the summary of the recorded results for the parallel and series equivalent circuit implementation is given in terms of the absolute error and standard deviation as reported in Table 6. It can be observed that the standard deviation values for the series model show very close agreement to the IEEE method for all the estimated motor parameters when compared to the parallel model.

\begin{tabular}{|c|c|c|c|c|c|c|c|c|}
\hline \multirow[t]{2}{*}{ Parameter } & \multicolumn{4}{|c|}{$\begin{array}{c}\text { Parallel equivalent circuit } \\
\text { model }\end{array}$} & \multicolumn{4}{|c|}{$\begin{array}{c}\text { Series equivalent circuit } \\
\text { model }\end{array}$} \\
\hline & $\begin{array}{l}\text { Reference } \\
\text { Values }\end{array}$ & $\begin{array}{c}\text { Parallel } \\
\text { Model }\end{array}$ & $\begin{array}{c}\text { Abs. } \\
\text { Error } \\
(\%)\end{array}$ & $\begin{array}{c}\text { Std. } \\
\text { Dev. }(\sigma)\end{array}$ & $\begin{array}{l}\text { Reference } \\
\text { Values }\end{array}$ & $\begin{array}{l}\text { Series } \\
\text { Model }\end{array}$ & $\begin{array}{c}\text { Abs. } \\
\text { Error } \\
(\%)\end{array}$ & $\begin{array}{c}\text { Std. } \\
\text { Dev. }(\sigma)\end{array}$ \\
\hline $\mathbf{R}_{\mathbf{r}}(\Omega)$ & 1.310 & 1.309 & 0.0763 & 0.0002 & 1.310 & 1.309 & 0.0763 & 0.0002 \\
\hline $\mathbf{X}_{\mathrm{Ir}}(\Omega)$ & 5.220 & 5.225 & 0.0958 & 0.0058 & 5.220 & 5.227 & 0.1341 & 0.0047 \\
\hline $\mathbf{X}_{\mathrm{ls}}(\Omega)$ & 3.500 & 3.505 & 0.1429 & 0.0039 & 3.500 & 3.502 & 0.0571 & 0.0032 \\
\hline $\mathbf{X}_{\mathrm{m}}(\Omega)$ & 98.015 & 97.964 & 0.0520 & 0.0341 & 98.500 & 98.482 & 0.0183 & 0.0717 \\
\hline $\mathbf{R}_{\mathrm{fe}}(\Omega)$ & 1400.700 & 1477.203 & 5.4618 & 75.741 & 6.893 & 6.829 & 0.9285 & 0.0646 \\
\hline
\end{tabular}

From Table 6, it can be observed that accurate parameter estimates are obtained for both the parallel and series equivalent circuits when compared to the reference values (obtained by the IEEE method 3). This is because the CSO algorithm as a global optimization method avoids convergence to an undesired local minimum. This can be observed by the percentage error values reported in Table 6. However, the standard deviation values, suggest that the series equivalent circuit model gives more repeatable results in terms of the magnetization branch parameters when compared to the parallel equivalent circuit.

\section{CONCLUSION}

In this paper, a simple, yet accurate method for IM parameter estimation is presented. The method relies on few external measurements of motor terminal quantities (voltage, current), shaft speed and temperature to formulate a distance criterion objection function for optimization. The objective function is defined based on the difference between the measured data and their corresponding estimates. The estimated parameters are determined using two different equivalent circuit implementations. From the experimental results, it was shown that the CSO algorithm was capable of estimating the IM parameters for both the parallel and series equivalent circuits implementations with acceptable levels of accuracies. It can be deduced from the results that the series equivalent circuit implementation gave more accurate and repeatable parameter estimates with less percentage errors when compared to the parallel equivalent circuit implementation.

\section{REFERENCES}

Abdelhadi, B.; A. Benoudjit.; and N. Nait-Said (2005). Application of genetic algorithm with a novel adaptive scheme for the identification of induction machine parameters, IEEE Trans. Energy Convers., 20 (2): 284-291.

Al-badri, M., P. Pillay.; and P. Angers. (2015). A Novel Algorithm for Estimating Refurbished Three-Phase Induction Motors Efficiency, IEEE Trans. Energy Convers. 30 (2): 615625 .
Alturas, A. M.; S. M. Gadoue.; B. Zahawi.; and M. A. Elgendy. (2016). On the Identifiability of Steady-State Induction Machine Models Using External Measurements, Energy Conversion IEEE Transactions, 31(1), 251-259.

Bechouche, A.; H. Sediki.; D. O. Abdeslam.; and S. Haddad. (2012). A Novel Method for Identifying Parameters of Induction Motors at Standstill Using ADALINE, IEEE Trans. on Energy Convers, 27 (1): 105-116.

Carraro, M. and Zigliotto, M. (2014). Automatic Parameter Identification of Inverter-Fed Induction Motors at Standstill, IEEE Trans. on Ind. Elect., 61 (9): 4605-4613.

Castaldi, P. and Tilli, A. (2005). Parameter Estimation of Induction Motor at Standstill with Magnetic Flux Monitoring, IEEE Trans. on Cont. Sys. Tech. 13 (3): 386-400.

Cirrincione, M.; M. Pucci.; G. Cirrincione.; and G. A. Capolino. (2005). Constrained minimization for parameter estimation of induction motors in saturated and unsaturated conditions, IEEE Trans. Ind. Electron., 52 (5): 1391-1402.

Fleiter, T.; W. Eichhammer.; and K. J. Schleih. (2011). Energy efficiency in electric motor systems: Technical potentials and policy approaches for developing countries, United Nations Ind. Organ. Rep.: pp. 1-34.

Haque, M. H. (2008). Determination of NEMA design induction motor parameters from manufacturer data, IEEE Trans. Energy Convers., 23 (4): 997-1004.

IEEE Standard 112. (2017). IEEE Standard Test Procedure for Polyphase Induction motors and Generators.

Kanakoglu, A. I.; A. G. Yetgin.; H. Temurtas.; and M. Turan. (2014). Induction motor parameter estimation using metaheuristic methods, Turkish Journal of Electrical Engineering \& Computer Sciences, 22: 1177-1192.

Lu, B.; W. Cao.; I. French.; K. J. Bradley.; and T. G. Habetler. (2007). Non-intrusive efficiency determination of in-service induction motors using genetic algorithm and airgap torque methods, Conf. Rec. - IAS Annu. Meet. IEEE Ind. Appl. Soc.: 1186-1192.

Lu, B.; T. G. Habetler.; and R. G. Harley. (2008). A Nonintrusive and In-Service Motor-Efficiency Estimation Method Using Air-Gap Torque With Considerations of Condition Monitoring, IEEE Trans. on Ind. Applications, 44 
(6): 1666-1674.

Meng, X.; Y. Liu.; and X. Gao. (2014). A new bioinspired algorithm: chicken swarm optimization, In Springer, Advances in Swarm Intelligence, 8794: 86-94.

Mohan, N. (2012). Advanced Electric Drives: Analysis, Control, and Modelling using MATLAB/SIMULINK, John Wiley \& Sons Inc., New Jersey (Chapters $2 \& 3$ ).

National Electrical Manufacturers Association (NEMA). (2006). NEMA MG 1-2006 for Motors and Gnerators.

Qu, C.; S. Zhao.; Y. Fu.; and W. He. (2017). Chicken Swarm Optimization Based on Elite Opposition-Based Learning, Mathematical Problems in Engineering, 2017, Hindawi, https://doi.org/10.1155/2017/2734362.

Ranta, M. and Hinkkanen, M. (2013). Online identification of parameters defining the saturation characteristics of induction machines, IEEE Trans. Ind. Appl., 49 (5): 2136-2145.

Reed D. M.; H. F. Hofmann.; and J. Sun. (2016). Offline Identification of Induction Machine Parameters With Core Loss Estimation Using the Stator Current Locus, IEEE Trans. on Energy Convers, 31 (4): 1549-1558.

Sandro C. L.; A. C. Carlos.; N. J. Wengerkievicz.; N. S. Batistela.; A. S. Pedro.; and Y. B. Anderson. (2017). Induction motor parameter estimation from manufacturer data using genetic algorithms and heuristic relationships, IEEE
Power Electronics Conference (COBEP) 2017 Brazilian, 1-6, 2017.

Seesak, J. and Panthep, L. (2009). Parameter Estimation of Three-Phase Induction Motor by using Genetic Algorithm, Journal of Electrical Engineering \& Technology 4 (3): 360364.

Toliyat, H. A.; E. Levi; and M. Raina. (2003). A Review of RFO Induction Motor Parameter Estimation Techniques, IEEE Trans. on Energy Convers, 18 (2): 271-283.

Waide, P. and Brunner, C. U. (2011). Energy-Efficiency Policy Opportunities for Electric Motor-Driven Systems, Int. Energy Agency, Energy Effic. Ser. Rep.: pp. 1-132.

Wang, K.; J. Chiasson.; M. Bodson.; and L.M. Tolbert. (2004). A nonlinear least-squares approach for identification of the induction motor parameters, Decision and Control 2004. CDC. 43rd IEEE Conference on, 4, 3856-3861.

Wu, D.; F. Kong.; W. Gao.; Y. Shen.; and Z. Ji. (2015). Improved chicken swarm optimization, IEEE Int. Conf. Cyber Technol. Autom. Control Intell. Syst. IEEE-CYBER: 681686.

Yang, S.; S. Yang.; Z. Xie.; M. Ma.; and X. Zhang. (2017). A new vector control strategy of induction motor based on iron loss model, Chinese Automation Congress (CAC) 2017, 3521-3526. 